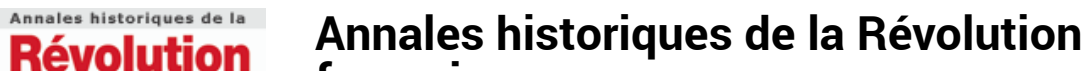 \\ française française
}

375 | janvier-mars 2014

Les Indes Orientales au carrefour des Empires

\section{Hélène BECQUET, Marie-Thérèse de France. L'orpheline} du Temple

Paris, Perrin, 2012

Pauline Lemaigre-Gaffier

\section{(2) OpenEdition \\ Journals}

Édition électronique

URL : https://journals.openedition.org/ahrf/13120

DOI : 10.4000/ahrf.13120

ISSN : 1952-403X

Éditeur :

Armand Colin, Société des études robespierristes

Édition imprimée

Date de publication : 1 mars 2014

Pagination : 238-240

ISBN : 978-2-200-9083-2790-8

ISSN : 0003-4436

Référence électronique

Pauline Lemaigre-Gaffier, " Hélène becquet, Marie-Thérèse de France. L'orpheline du Temple », Annales historiques de la Révolution française [En ligne], 375 | janvier-mars 2014, mis en ligne le 08 juillet 2014, consulté le 05 juillet 2021. URL : http://journals.openedition.org/ahrf/13120 ; DOI : https://doi.org/ 10.4000/ahrf. 13120

Ce document a été généré automatiquement le 5 juillet 2021.

Tous droits réservés 


\title{
Hélène BECQUET, Marie-Thérèse de France. L'orpheline du Temple
}

Paris, Perrin, 2012

\author{
Pauline Lemaigre-Gaffier
}

\section{RÉFÉRENCE}

Hélène BECQUET, Marie-Thérèse de France. L'orpheline du Temple. Paris, Perrin, 2012, ISBN 978-2-262-03244-9, 24€.

1 La biographie qu'Hélène Becquet a tirée de sa thèse analyse les transformations de la culture politique au tournant des XVIII $^{\mathrm{e}}$ et $\mathrm{XIX}^{\mathrm{e}}$ siècles à travers les vicissitudes d'une figure princière qui fut l'un des lieux de cristallisation de l'idéologie royaliste et de l'imaginaire contre-révolutionnaire. S'inscrivant dans le renouvellement de l'histoire politique qui analyse des trajectoires individuelles et collectives de l'Ancien Régime, de la Révolution et des monarchies censitaires, cet ouvrage rend moins compte d'une existence que des usages politiques des représentations qui lui furent associées. La question centrale est celle de la dignité royale, des reconfigurations de ses fondements et de ses modalités: transmission, adaptation et réappropriation d'un héritage politique et symbolique $\mathrm{y}$ sont déclinées autour de quelques thèmes structurant l'ouvrage par-delà sa trame biographique.

Il s'agit tout d'abord du cérémonial, dont la Maison des Enfants de France constituée à la naissance de la princesse est le premier observatoire. Bien que celui-ci dénote l'importance accordée par Louis XVI et Marie-Antoinette à la mise en scène de la dignité royale, il fut inculqué à leur fille aînée que leurs réformes, interprétées comme des manquements à l'étiquette, avaient causé leur perte. Du fait de cette double transmission, Marie-Thérèse conserva un profond attachement aux règles de la vie de cour, maintenue envers et contre tout dans ses multiples résidences d'exil. Les Tuileries n'en furent pas moins le terrain de quelques innovations - notamment le recours à l'espace urbain et aux voyages - et de débats - tels que la question des critères à 
appliquer dans la composition des maisons royales. Devenue duchesse d'Angoulême puis dauphine, Marie-Thérèse chercha à faire primer la qualité sociale, attestée par l'appartenance aux structures d'Ancien Régime, sur la nouvelle hiérarchie des fonctions, tout en intégrant partiellement des critères politiques inédits - c'est-à-dire la fidélité à la cause royaliste.

3 Le personnage de Marie-Thérèse met aussi en lumière les tensions entre logiques dynastiques et logiques nationales au tournant des XviII et $\mathrm{xIX}^{\mathrm{e}}$ siècles. En refusant d'épouser un archiduc, Marie-Thérèse asseoit sa réputation de princesse "française ", ce que la propagande royaliste instrumentalisera à la Restauration. Sollicitant l'Espagne et l'Angleterre au moment des Cent-Jours, Marie-Thérèse témoigne en fait rapidement d'un contre-modèle qui assimile le destin de la Nation et celui de la dynastie, en rupture avec la définition révolutionnaire de la Nation. C'est en vain que les légitimistes ayant intégré le nationalisme révolutionnaire lui déconseilleront après 1830 de quitter l'Autriche pour un autre lieu d'exil et de marier le duc de Bordeaux avec une princesse russe plutôt qu'une Habsbourg - afin de laver la famille royale du soupçon d'antipatriotisme.

4 En troisième lieu, l'ouvrage contribue à la réflexion sur les reconfigurations par la Révolution du rôle politique et symbolique des femmes - à l'instar des travaux de Guillaume Mazeau sur Charlotte Corday. Marie-Thérèse a reçu à sa naissance le titre de «Fille de France » : participant du sang royal, elle participe de l'essence du pouvoir en dépit de la loi salique. Tout en conservant à la monarchie son caractère héréditaire, la constitution de 1791 vide en revanche de leur sens politique et mystique les notions de "maison", de "dynastie » ou de "sang ». Privant de rôle officiel les femmes de la famille royale, dont tous les faits et gestes étaient jusque-là publics, la Révolution leur impose le repli sur la sphère privée qu'elle impose aux femmes à l'échelle de la Nation. Les royalistes envisagent au contraire la suppression de la loi salique au profit de la princesse qui cumule la plus grande proximité généalogique au dernier souverain, la légitimité du malheur et un capital de sympathie et d'adhésion au sein de la société française. La question de son accession au trône devient ainsi un véritable serpent de mer de la vie politique, qui ressurgit à chaque crise - en 1795, au moment où Louis XVIII doit quitter Mitau pour l'Angleterre, lors des Cent-Jours, de l'assassinat du duc de Berry ou des Trois Glorieuses.

5 Le personnage incarné par " Madame ", y compris à son corps défendant, porte en effet la marque des transformations imposées à la culture politique traditionnelle par ceuxlà même qui cherchent à en perpétuer les principes. Cette tension s'exprime par exemple au moment où Marie-Thérèse retrouve non seulement son statut de Fille de France, mais se voit parée des attributs de la souveraineté dont elle est garante - qu'il s'agisse du rôle que son oncle lui fait jouer à la cour ou de ses portraits officiels. Le culte du sang des martyrs tend alors à l'emporter sur les lois dynastiques traditionnelles, ce qui la place au centre du système de légitimation et de représentation de la famille royale. Fille de Louis XVI, dont l'exécution a donné corps à l'assimilation de la figure royale et de la figure christique et dont elle a partagé les souffrances, elle authentifie donc, par sa présence et ses mythiques yeux rougis, le discours royaliste sur le sacrifice que la famille royale a fait pour sauver la France.

6 Cette image de "reine des douleurs " culmine après 1830 alors même que MarieThérèse refuse de se prêter à toute propagande. Son personnage participe en effet paradoxalement des mutations globales des régimes de la renommée. Si cette 
thématique (voir les travaux d'Antoine Lilti, Figures publiques. Aux origines de la célébrité, à paraitre chez Fayard en 2014) n'est pas explicitée par l'auteur, la princesse est indéniablement au cœur des processus de la célébrité - lesquels passent notamment par la surveillance et la mise en récit de l'existence du personnage en question. Après la Terreur et au moment du regain de vigueur du royalisme, les admirateurs de la princesse vont ainsi jusqu'à louer un appartement en face du Temple : on la scrute pour rendre compte de ses faits et gestes quotidiens et mieux la réinventer. Plus largement, on en fait l'héroïne de chansons, de poèmes et de récits au goût du jour - roman noir, ballades à la manière d'Ossian -, qui ont sa souffrance et son histoire, et non son rang, pour principal ressort. Louis XVIII exploite lui aussi la légitimité sacrificielle de sa nièce en recourant à la publication et à la fictionnalisation. Chassé de Mitau par le tsar en 1801, il associe la proclamation d'un manifeste de l'idéologie royaliste à la mise en scène de sa nièce sous les traits d'une moderne Antigone. À la Restauration, il fait publier les mémoires que "l'orpheline » a écrits sur son emprisonnement dans un volume qui rassemble aussi les souvenirs de deux fidèles serviteurs - Cléry et Hue -, afin de proposer une version royaliste autorisée de l'épisode du Temple. C'est le même mécanisme qui prévaut avec la publication de la lettre que la duchesse d'Angoulême envoie à son oncle réfugié à Gand alors qu'elle défend à Bordeaux les droits de la royauté en 1815 : cette figure politique féminine devient alors double et à l'héroïne des royalistes répond alors logiquement la virago des défenseurs de l'héritage révolutionnaire et impérial. Marie-Thérèse ne se prête qu'avec réticence à ces manœuvres mais y participe paradoxalement en perpétuant certaines pratiques d'Ancien Régime. De même que les souverains faisaient don à leurs serviteurs de leurs effets ou que les moines de Saint-Denis transformaient poêles et manteaux utilisés lors des funérailles en ornements liturgiques, elle distribue les reliques collectionnées en mémoire de ses parents. Entre pratique cultuelle et réification de la personne célèbre, ces gestes font écho au souci des dames de Bordeaux de conserver des fragments de son vêtement ou à celui de Céleste de Chateaubriand de transformer son manteau en ornement pour la chapelle de l'institution qu'elle patronnait. La dévotion dont la princesse et ses parents faisaient l'objet se trouvait donc elle aussi entre Ancien Régime et Révolution.

7 Aussi fluide qu'évocateur à la lecture, l'ouvrage d'Hélène Becquet ne cède jamais à la facilité de l'anecdote ou de l'empathie. D'une grande qualité formelle, il explore en outre de manière exhaustive la place de cette figure princière et féminine dans la vie politique du tournant des $\mathrm{XVIII}^{\mathrm{e}}$ et $\mathrm{XIX}^{\mathrm{e}}$ siècles. Si Marie-Thérèse a pu jouer en certaines circonstances un véritable rôle politique, ce dernier s'est avant tout construit malgré elle, dans des fictions par le biais desquelles son personnage a participé à l'émergence de formes nouvelles d'adhésion politique jusqu'au sein des factions politiques les plus réactionnaires. Pour mener à bien cette démonstration, l'auteur a mis au jour un important corpus de représentations aussi bien écrites que visuelles. On renverra à la thèse de l'École des Chartes soutenue par Hélène Becquet en 2004 pour prendre une connaissance de ce corpus plus ample que celle donnée par les quatre textes proposés en annexe et par le portrait de Fuger placé en couverture. Si le fait même que la fiction s'éteigne avec son personnage garantit sa cohérence au projet biographique et historique de l'ouvrage, l'articulation de la trame de l'existence avec l'analyse des représentations auxquelles celle-ci donna lieu n'est pas toujours tout à fait convaincante - a fortiori dans la mesure où Marie-Thérèse n'en fut ni maîtresse, ni même sans doute consciente. Dans cette perspective, on regrette d'autant plus que 
l'analyse quantitative et qualitative de ces représentations, de leurs producteurs, de leurs commanditaires et de leur réception n'ait pu être menée ou mieux exposée. On se demande à quel point cette enquête, même de moindre ampleur du fait de son objet, aurait croisé les résultats de celle de Corinne Legoy (sur les thuriféraires du pouvoir qui ont éclos spontanément sous la Restauration). En l'absence de comparaison, on tend donc à s'interroger sur le poids exact de la personne et du personnage de MarieThérèse dans cette "monarchie sentimentale " (Natalie Scholz) que fut à certains égards la Restauration. L'entrée dans la vie de la fille de Louis XVI par les représentations n'en construit pas moins une grille de lecture très pertinente pour comprendre la gestation de la culture politique royaliste et contre-révolutionnaire, longtemps délaissée par l'historiographie. 